\title{
Sistem Identifikasi Usia Manusia pada Citra Panoramic Radiograph Gigi Molar Pertama
}

\author{
BANYUBIRU $^{1}$, HILMAN FAUZI ${ }^{2}$, FAHMI OSCANDAR ${ }^{3}$ \\ 1,2Fakultas Teknik Elektro, Universitas Telkom, Bandung, Indonesia \\ ${ }^{3}$ Fakultas Kedokteran Gigi, Universitas Padjajaran, Bandung, Indonesia \\ Email: banyubiru@student.telkomuniversity.ac.id
}

Received 24 April 2020 | Revised 18 Mei 2020 | Accepted 25 Juni 2020

\begin{abstract}
ABSTRAK
Odontologi forensik merupakan sebuah cabang ilmu forensik yang melakukan proses identifikasi berdasarkan gigi. Gigi merupakan salah satu bagian tubuh manusia paling kuat kuat. Dalam masa pertumbuhan, gigi manusia mengalami degeneratif pada usia tertentu, sehingga gigi dapat menjadi media dalam proses identifikasi usia. Pada penelitian ini, dirancang sistem pengolahan citra yang dapat mendeteksi usia manusia pada citra radiograf panoramik gigi. Sistem ini menggunakan metode Binary Large Object dan Decision Tree. Berdasarkan hasil pengujian, sistem dapat mendeteksi usia berdasarkan citra gigi molar pertama dengan tingkat akurasi lebih dari 80\%, pada saat menggunakan parameter structuring element jenis Disk dengan jari-jari 4 piksel, ciri area dan rasio pulpa, serta jenis algoritma pada decision tree yaitu curvature dengan jumlah 50 percabangan.
\end{abstract}

Kata kunci: citra radiograf panoramik, pulpa gigi, molar pertama, decision tree, binary large object

\begin{abstract}
Forensic odontology is a branch of forensic science that carries out dental identification processes. Teeth are one of the strongest parts of the human body. In the period of growth, human teeth degenerative at a certain age, so that teeth can be a medium in the process of age identification. In this study, an image processing system was designed that could detect human age on dental panoramic radiographs. This system using the Binary Large Object and Decision Tree methods. Based on the test results, the system can detect age based on the image of the first molar with an accuracy level of more than 80\%, when using a Disk type structuring element parameter with a radius of 4 pixels, the area and pulp ratio features, and the type of algorithm in the decision tree, namely curvature with the number of 50 branches.
\end{abstract}

Keywords: panoramic radiograph image, teeth pulp, first molar, decision tree, binary large object 
Perancangan Sistem Identifikasi Usia Manusia pada Citra Panoramic Radiograph Gigi Molar Pertama

\section{PENDAHULUAN}

Identifikasi forensik berperan penting untuk mengungkap identitas manusia yang sulit dikenali. Identifikasi ini bertujuan untuk memenuhi hak jenazah agar dapat dikembalikan kepada keluarga dan dikubur secara layak. Di Indonesia ilmu forensik yang sudah sering digunakan untuk identifikasi individu. Objek yang digunakan untuk identifikasi tersebut diantaranya adalah sidik jari. Pada dari kondisi tertentu, sidik jari akan sangat sulit dikenali dan bahkan hancur. Oleh karena itu sidik jari tidak dapat dijadikan bukti fisik yang kuat. Salah satu bagian tubuh yang memiliki daya tahan yang tinggi yaitu gigi. Cabang ilmu forensik yang secara khusus mempelajari dari gigi yaitu odontologi forensik.

Odontologi forensik merupakan sebuah disiplin ilmu yang menerapkan pengetahuan mengenai gigi untuk membantu memecahkan masalah yang berhubungan dengan forensik dalam upaya penegakan hukum (Budi, 2014). Odontologi forensik menganalisis gigi individu baik masih hidup maupun yang telah meninggal salah satunya melakukan identifikasi usia melalui gigi. Gigi dapat digunakaan sebagai media dalam prakiraan usia karena berbagai keunggulannya. Gigi mengalami tahap pertumbuhan dan perkembangan, serta perubahan degeneratif yang terjadi pada usia tertentu, sehingga dapat digunakan sebagai indikator prakiraan usia individu dari sejak usia intrauterin sampai usia dewasa (Putri, dkk, 2013). Dalam masa perkembangannya pulpa akan mengalami penyempitan seiring bertambahnya usia. Oleh karena itu, luas pulpa gigi dapat digunakan sebagai objek untuk identifikasi usia.

Dalam penelitian ini menggunakan radiograf panoramik pulpa gigi molar pertama. Penelitian ini didasari oleh penelitian pada citra x-ray yang kemudian dilakukan peneltian mengenai identifikasi usia manusia berdasarkan citra panoramik gigi. Pada penelitian terdahulu, penelitian mengenai deteksi usia berdasarkan citra radiograf panoramik pada gigi molar pertama sudah pernah dilakukan menggunakan berbagai metode yang ada diantaranya Discrete Cosine Transform (DCT), Histogram of Oriented Gradient (HOG), Gray Level Cooccurrence Matrix (GLCM) dan Discrete Wavelet Transform (DWT). Untuk metode Histogram of Oriented Gradient telah dilakukan penelitian oleh (Kurniawati, dkk, 2018) yang menghasilkan nilai akurasi tertinggi 68,33\%, lalu dengan metode Discrete Cosine Transform oleh (Rachmawati, dkk, 2018) menghasilkan hasil akurasi tertinggi sebesar $69,11 \%$, dengan metode Gray Level Co-occurence Matrix oleh (Kusumaningtias, dkk, 2019) memperoleh nilai akurasi tertinggi sebesar $68,04 \%$, kemudian dengan menggunakan metode Discrete Wavelet Transform oleh (Haris, dkk, 2019) yang menghasilkan nilai akurasi sebesar $71,13 \%$. Perolehan hasil tersebut dipengaruhi oleh proses segmentasi area pulpa yang kurang detail. Sehingga dalam penelitian ini diharapkan adanya peningkatan dari penelitian sebelumnya. Dan dalam penelitian ini telah dirancang sistem berbasis pengolahan citra digital untuk mengidentifikasi usia manusia berdasarkan citra radiograf panoramik pada gigi molar dengan menggunakan metode Binary Large Object (BLOB). Citra hasil ekstraksi ciri akan diklasifikasikan berdasarkan kelasnya dengan menggunakan metode klasifikasi Decision Tree. Deteksi $B L O B$ dapat membedakan warna yang memiliki gradasi tipis sehingga diharapkan mampu meningkatkan performa sistem dari penelitian sebelumnya.

\subsection{Odontologi Forensik}

Odontologi Forensik atau dikenal sebagai ilmu kedokteran gigi forensik merupakan penerapan ilmu kedokeran gigi dalam lembaga penegak hukum yang bertujuan untuk memberikan informasi melalui pemeriksaan gigi (George, dkk, 2008). Odontologi forensik akan mengidentifikasi jasad untuk membantu dalam administrasi peradilan. Gigi dapat diandalkan dalam identifikasi forensik. Hal ini dikarenakan gigi mempunyai daya tahan yang tinggi, dapat bertahan terhadap perubahan suhu yang ekstrim (Senn \& Stimson, 2010). 


\subsection{Gigi Manusia}

Di dalam tubuh manusia, gigi berperan sebagai sebagai organ pada sistem pencernaan mekanik. Gigi disusun oleh tiga jaringan mineral keras yaitu dentin, enamel dan sementum. Selain jaringan keras, gigi juga tersusun oleh sebuah jaringan lunak yang disebut pulpa (Rashmi, Basavaraj, NK, \& Rathore, 2014). Gigi manusia tidak semuanya sama. Berdasarkan bentuk dan fungsinya, gigi manusia dibagi menjadi empat kelas yaitu gigi seri (incisors), gigi taring (canine), gigi geraham depan (premolar) dan gigi geraham belakang (molar).

\subsubsection{Gigi Molar}

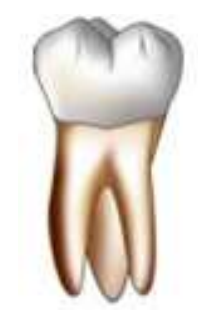

\section{Gambar 1. Gigi Geraham (Rashmi, dkk., 2014)}

Dari Gambar 1 dapat dilihat bahwa gigi geraham merupakan gigi dengan permukaan puncak yang paling luas apabila dibandingkan jenis gigi lainnya. Ciri utama gigi ini memiliki permukaan yang luas dan memiliki tiga puncak gigi. Dapat dikatakan fungsi gigi geraham ini yaitu untuk menggiling makanan, ini dikarenakan permukaan gigi ini yang luas

\subsubsection{Pulpa Gigi}

Pulpa gigi adalah sebuah jaringan ikat yang terletak di dalam gigi. Jaringan ikan tersebut disusun oleh struktur seperti arteri, vena, sistem limfatik, dan saraf. Fungsi primer dari pulpa yaitu membentuk dentin gigi. Ketika gigi baru saja erupsi maka luas pulpa gigi besar. Lalu luas pulpa akan menjadi semakin kecil saat gigi selesai melakukan erupsi (Nelson, 2014).

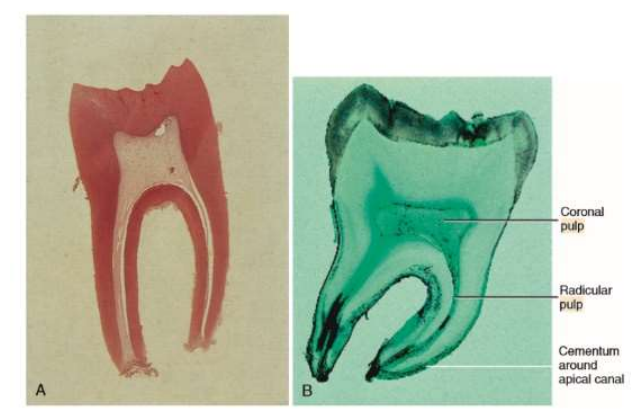

Gambar 2. Pulpa Gigi (Nelson, 2014)

Pada Gambar 2 diperlihatkan gigi A yang merupakan gigi muda dan memiliki ukuran pulpa relatif besar. Pada gigi B rongga pulpa menjadi lebih kecil dan semakin terbatas seiring bertambahnya usia (Nelson, 2014).

\subsection{Radiografi Panoramik}

Radiografi Pamoramik adalah teknik untuk menghasilkan gambar tunggal dari struktur gigi mulai lengkung gigi rahang atas dan rahang bawah serta struktur pendukungnya. Selama proses pengambilan citra, pasien dalam keadaan tidak bergerak sedangkan sumber x-ray dan sensor radiografi bergerak berlawanan arah pada satu atau lebih pusat rotasi (Watanabe, dkk, 2017). Dalam Gambar 3 merupakan contoh citra radiograf panoramik gigi manusia. 


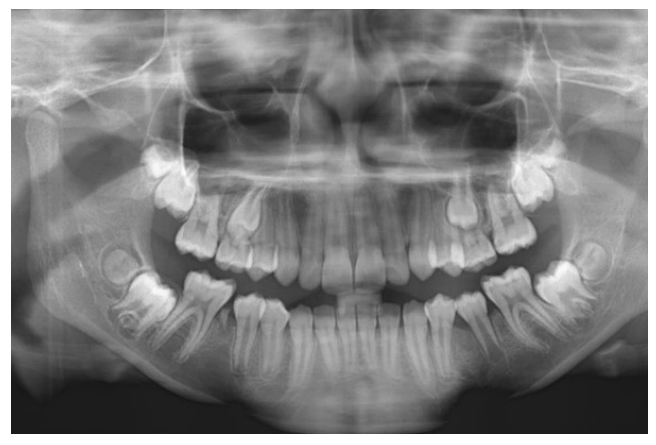

Gambar 3. Citra Radiograf Panoramik

Citra radiograf panoramik banyak digunakan karena beberapa kelebihannya. Dengan menggunakan radiograf panoramik visualisasi ruang pulpa dan saluran pulpa dengan radiografi digital akan menambah apa yang telah ditemukan secara klinis (Rashmi, dkk, 2014).

\subsection{Morfologi Citra}

Salah satu teknik pengolahan citra yang dapat dilakukan pada citra biner adalah morfologi citra. Operasi morfologi merupakan operasi yang biasa dilakukan untuk citra yang berbentuk biner (hitam-putih) yang bertujuan untuk mengubah struktur dan bentuk objek tertentu yang terdapat di dalam citra. Pada dasarnya operasi morfologi akan melibatkan dua array piksel. Array pertama merupakan citra yang akan dilakukan operasi morfologi, sedangkan untuk array kedua dinamakan sebagai kernel atau structuring element. Ada dua operasi yang sangat mendasar bagi operasi morfologi yaitu operasi dilasi dan erosi. Terdapat dua operasi lain yang sangat berguna dalam pengolahan citra digital adalah opening dan closing, yang kedua operasi tersebut didasar dan dibentuk melalui dua operasi dasar itu (Kadir \& Susanto, 2013).

\subsection{Otsu Thresholding}

Thresholding merupakan sebuah teknik dalam mengubah citra ke dalam bentuk biner yang proses dilakukan berdasarkan nilai threshold yang diambil dari suatu piksel dan pada umumnya berdasarkan tingkat keabuan pada citra. Suatu piksel yang memiliki tingkat keabuan yang lebih tinggi daripada nilai threshold akan dikategorikan sebagai objek, dan sebaliknya untuk piksel yang memiliki intensitas keabuan kurang dari nilai threshold akan dikategorikan sebagai background (Jafar, dkk, 2018). Dan Secara matematis metode thresholding dapat dituliskan dengan Persamaan (1):

$$
g(x, y)=\left\{\begin{array}{l}
1 \text { if } f(x, y) \geq T \\
0, \text { if } f(x, y)<T
\end{array}\right.
$$

Dari Persamaan (1), $g(x, y)$ mewakili citra biner, untuk $f(x, y)$ merupakan citra grayscale dan $T$ menyatakan nilai threshold.

Selanjutnya terdapat sebuah Teknik dalam mencari nilai threshold yaitu thresholding otsu. Mencari nilai threshold dengan menggunakan metode otsu yaitu salah satu metode dalam proses segmentasi citra digital dengan menggunakan nilai ambang yang didapat secara otomatis dari skala warna abu-abu pada citra. Nilai dari threshold tersebut berkisar antara 0 sampai dengan 255 (Syafi'i, dkk, 2016). Dalam mencari nilai threshold tersebut diawali dengan mencari probabilitas setiap piksel dalam level tertentu yang dinyatakan dalam Persamaan (2) berikut: 


$$
P_{i}=\frac{n i}{N}
$$

Untuk $P_{i}$ mewakili nilai probabilitas piksel ke- $i$, ni merupakan jumlah piksel dengan tingkat keabuan $i$, dan $N$ adalah total jumlah piksel pada citra. Setelah mendapatkan nilai probabilitas tersebut selanjutnya dilakukan perthitungan untuk mencari nilai jumlah kumulatif yang dituliskan dengan Persamaan (3):

$$
w(k)=\sum_{i=0}^{k} P_{i}
$$

Dimana $w(k)$ mewakili nilai kumulatif dari probabilitas piksel dan Nilai $\mathrm{k}$ berkisar antara 0 sampai dengan $L-1$, dengan nilai $L=256$. Setelah mendapat nilai kumulatif, berikutnya adalah proses untuk menghitung rerata kumulatif (cumulative mean) yang secara matematis dituliskan dalam Persamaan (4) berikut:

$$
u(k) \sum_{i=0}^{k} i \times P_{i}
$$

Untuk $u(k)$ mewakili nilai rerata kumulatif dari probabilitas piksel. Dan selanjutnya proses yang dilakukan yaitu menghitung rerata intensitas global yang dituliskan dalam Persamaan (5) berikut:

$$
u_{t}(k) \sum_{i=0}^{k} i \times P_{i}
$$

Dari persamaan diatas $u_{t}(k)$ mewakili nilai rerata intensitas global. Dan setelah semua nilai didapat, selanjutnya dilakukan perhitungan untuk mencari nilai varian antar kelas yang diformulasikan sebagai berikut:

$$
\alpha_{B}^{2}(k)=\frac{\left[u_{t}(k)-u(k)\right]^{2}}{w(k)[1-w(k)]}
$$

Setelah didapatkan nilai dari perhitungan varian antar kelas kemudian dilakukan pencarian nilai yang paling maksimal. Proses pencarian nilai maksimal tersebut dapat ditulis secara matematis sebagai berikut:

$$
\alpha_{B}^{2}\left(k^{*}\right)=\operatorname{Max}_{1 \leq x \leq L} \alpha_{B}^{2}(k)
$$

Dari Persamaan (7) akan didapatkan nilai threshold yang paling besar akan digunakan sebagai threshold atau nilai ambang. Dan untuk nilai threshold akan berbeda dari setiap citra yang diolah (Syafi'i, dkk., 2016).

\subsection{Binary Large Object}

$B L O B$ merupakan sebuah daerah dari piksel yang saling berdekatan pada suatu citra tertentu dengan nilai logika yang sama. Konsep $B L O B$ yaitu melakukan pengelompokan antara satu piksel dengan piksel lain yang hampir serupa ke dalam satu region. Metode $B L O B$ ini memiliki tujuan untuk memisahkan objek $B L O B$ ke dalam bentuk biner, yaitu 0 dan 1 . Setiap piksel yang tergabung pada daerah $B L O B$ akan berada di bagian atas dengan logika bernilai 1 , sedangkan piksel yang berada di bagian bawah daerah $B L O B$ disebut sebagai background dengan nilai logika 0 (Surashadarti, dkk, 2018). Proses ekstraksi dengan metode $B L O B$ lebih jelasnya dapat diilustrasikan dalam Gambar 4. 


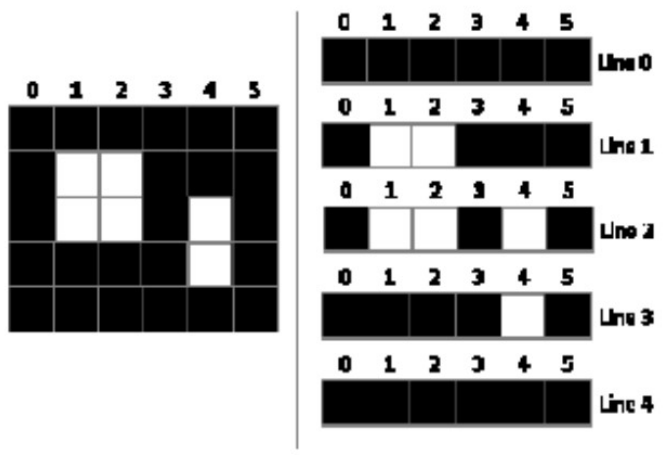

Gambar 4. Ilustrasi Metode $B L O B$

Metode deteksi $B L O B$ didasarkan pada representasi skala-ruang. Tujuan utama dari representasi skala-ruang tersebut yaitu untuk memahami struktur gambar pada semua tingkat resolusi. Detektor $B L O B$ dapat didasarkan pada gradasi, nilai eigen dan template pada citra. Gradasi digunakan untuk mendeteksi garis besar objek. Nilai eigen digunakan untuk menentukan panjang, lebar dan orientasi dari objek. Lalu template berguna untuk mencocokkan objek dengan bentuk yang telah ditentukan (Greensted, 2009).

\subsection{Decision Tree}

Decision tree merupakan sebuah metode klasifikasi yang digunakan sebagai pemodelan serangkaian pemecahan keputusan yang mengarah menuju solusi. Decision tree direpresentasikan menggunakan diagram yang terdiri dari daun dan sampul. Dimana sampul menyatakan keputusan sedangkan daun menyatakan solusi (Munir, 2012). Yang lebih jelasnya diilustrasikan pada Gambar 5.

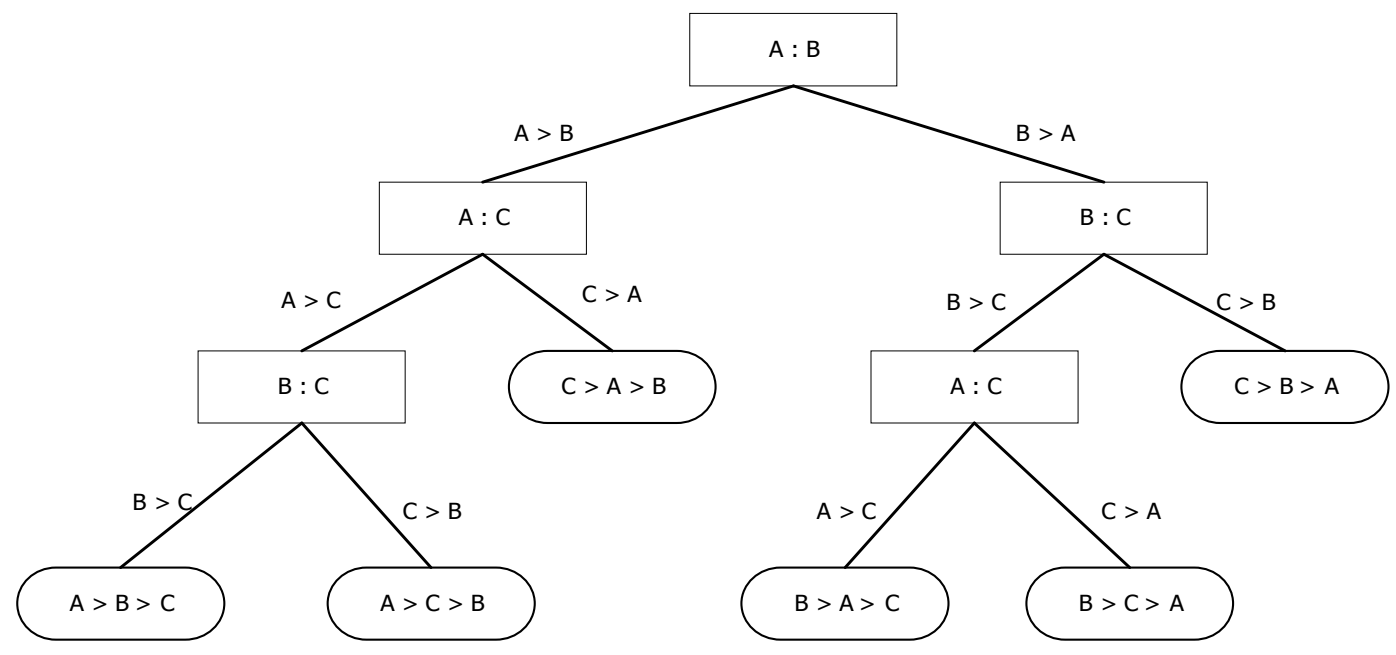

Gambar 5. Ilustrasi Decision Tree (Munir, 2004)

Dari Gambar 5 merupakan ilustrasi dari klasifikasi decision tree yang mana setiap simpul daun diberi label kelas. Dalam proses pemilihan atribut untuk menjadi root node dilakukan berdasarkan atas ukuran gain informasi dari masing-masing atribut. Gain informasi mengukur seberapa baik suatu atribut memisahkan training ke dalam kelas target (Maulana, 2016). Atribut dengan gain informasi tertinggi akan dipilih. Atribut dengan gain informasi tertinggi akan dipilih. Untuk perhitungan mencari nilai gain dapat dilihat pada Persamaan (8) di bawah. 


$$
G(S, A)=\operatorname{Entropy}(S)-\sum_{i=1}^{n} \frac{\left|S_{i}\right|}{|S|} \times \operatorname{Entropy}\left(S_{i}\right)
$$

Dalam Persamaan (8) $G(S, A)$ mewakili nilai gain informasi dari suatu atribut, $S$ mewakili himpunan kasus, $A$ mewakili nilai atribut, $n$ mewakili jumlah partisi dari atribut, $\left|S_{i}\right|$ jumlah kasus pada partisi ke-i, $S$ mewakili jumlah kasus dan entropy menyatakan ukuran ketidakpastian secara probabilistik yang dirumuskan pada Persamaan (9) di bawah ini.

$$
\operatorname{Entropy}(S)=\sum_{i=1}^{n} P_{i} \times \log _{2} P_{i}
$$

Dalam Persamaan (9) untuk $P_{i}$ merupakan peluang bahwa suatu sampel akan masuk ke kelas $S$. Tujuan didapatkan nilai entropy adalah untuk mendapatkan nilai gain informasi yang berguna untuk menentukan ukuran efektifitas suatu atribut dalam melakukan klasifikasikan data.

\section{METODOLOGI PENELITIAN}

\subsection{Desain Sistem}

Penelitian ini merancang dan menganalisis sebuah sistem berbasis pengolahan citra yang mampu mendekteksi usia manusia melalui citra panoramik radiograf. Secara garis besarnya sistem dibagi menjadi empat proses yang berlangsung secara kaskade. Gambaran umum proses tersebut tersebut direpresentasikan melalui blok diagram pada Gambar 6.

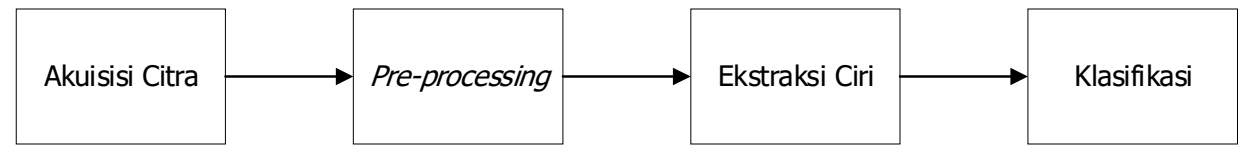

Gambar 6. Blok Diagram Sistem

Setiap blok diagram pada Gambar 6 mewakili proses yang berbeda. Proses pertama diawali dengan akuisisi citra dengan masukan berupa citra panoramik. Selanjutnya citra akan memasuki tahap pre-processing, tahapan ini bertujuan untuk mendapatkan kualitas yang lebih baik pada citra yang akan diteliti. Kemudian citra memasuki tahap ekstraksi ciri, lalu proses terakhir yaitu citra akan diklasifikasikan berdasarkan kelas yang ditentukan.

\subsection{Akuisisi Citra}

Proses memperoleh citra masukan pada tugas akhir ini yaitu didapat dari RSGM Fakultas Kedokteran Gigi Universitas Padjajaran. Data radiograf panoramik gigi yang didapatkan berupa citra digital. Resolusi data rata-rata berkisar pada 2840x1532 piksel dan berukuran 12 MB. Serta untuk tipe file data yang diperoleh yaitu *jpg. Data tersebut dapat dilihat pada Gambar 7.

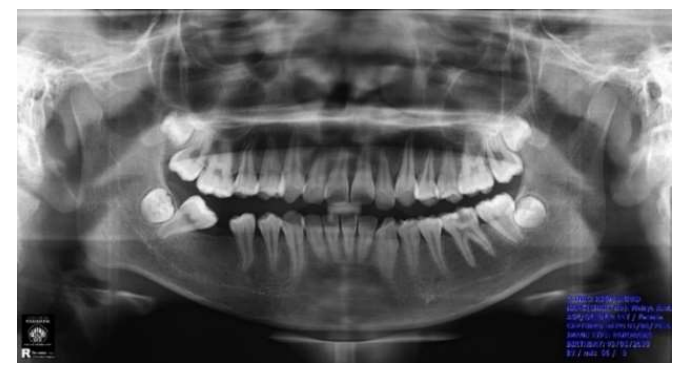

Gambar 7. Contoh Data Citra Gigi 
Data yang digunakan dalam penelitian ini merupakan data sekunder berupa radiograf panoramik gigi yang diambil dari instalasi Radiologi RSGM FKG Unpad. Jumlah data yang diambil dalam penelitian ini adalah sebanyak 188 dengan rentang usia 14 hingga 60 tahun. Dan pada masing-masing umurnya memiliki sebanyak 4 sampel dari individu yang berbeda yang kemudian dari 188 citra tersebut diambil 2 buah gigi molar pertama bagian bawah sehingga jumlah datasetyang digunakan pada penelitian ini berjumlah 376 buah data.

\subsection{Pre-processing}

Pada pre-processing ini merupakan proses awal dilakukan sebelum citra memasuki proses selanjutnya. Tujuan dari pre-processing yaitu untuk menyeragamkan dan meningkatkan kualitas data yang akan diolah. Pre-processing pasa sistem ini direpresentasikan dalam flowchart pada Gambar 8 berikut:

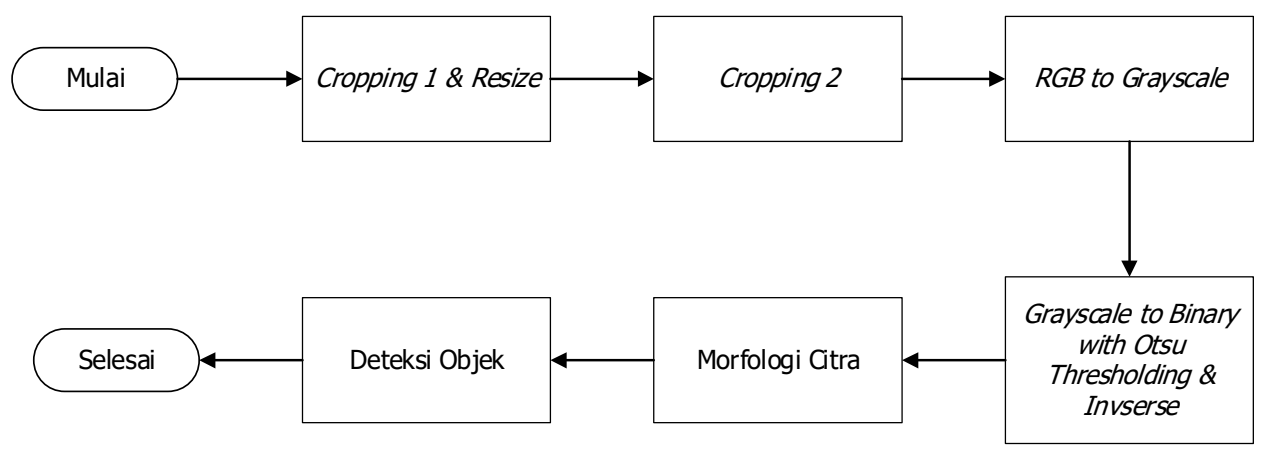

\section{Gambar 8. Diagram Alur Pre-processing}

\subsubsection{Cropping 1 \& Rezize}

Proses cropping digunakan untuk mangambil bagian gigi molar pertama rahang bawah kanan dan kiri yang akan digunakan dalam penelitian. Selain itu juga dalam cropping menggunakan photoshop ini sekaligus dilakukan resize yang bertujuan untuk membuat resolusi pada citra menjadi seragam dengan resolusi 170×305 piksel. cropping 1 ini bertujuan untuk menghitung luas gigi secara keseluruhan. Dan selanjutnya akan dilakukan proses cropping 2 untuk menghitung bagian pulpa.

\subsubsection{Cropping 2}

Setelah itu, citra akan masuk ke proses di dalam MATLAB, dan disini terdapat dua masukan citra yang di-crop secara manual dan citra yang di-crop lagi secara otomatis menggunakan MATLAB. Proses cropping di dalam MATLAB ini agar citra input hanya terfokus pada bagian pulpa. Dan untuk citra hasil cropping 1 dengan keadaan gigi utuh bertujuan untuk mengitung luas keseluruhan gigi.

\subsubsection{RGB to Grayscale}

Agar mempercepat proses deteksi, citra yang masih berjenis RGB dikonversi menjadi citra grayscale. Citra yang awalnya memiliki tiga layer dikonversi kedalam citra yang hanya memiliki satu layer saja.

\subsubsection{Grayscale to Binary \& Inverse}

Selanjutnya citra grayscale diubah ke dalam bentuk citra biner. Dalam penelitian ini, mengubah citra grayscale ke dalam citra biner dilakukan dengan melakukan thresholding adaptive. Nilai threshold itu didapatkan dengan menyesuaikan dengan tingkat keabuan yang terdapat pada citra grayscale sebelumnya. Setelah citra ditransformasikan ke dalam bentuk biner, selanjutnya dilakukan operasi inverse citra. Tujuan dari penggunaan operasi invers ini adalah 
untuk membuat citra negatif dari citra biner yang telah didapatkan sebelumnya. Hal ini dikarenakan objek yang dibutuhkan untuk diteliti pada citra yaitu pada bagian pulpa yang berada di tengah yang sebelumnya terdeteksi sebagai latar belakang (bernilai 0 ).

\subsubsection{Mofologi Citra}

Operasi morfologi citra merupakan suatu proses yang bertujuan untuk memperbaiki bentuk objek pada citra asli. Operasi morfologi yang akan dilakukan pada penelitian ini diantaranya yaitu erosi dan opening. Erosi atau pengikisan yaitu teknik morfologi citra yang digunakan untuk memperkecil atau mengikis tepi objek. Dengan dilakukannya erosi citra ini, bertujuan untuk memisahkan atau memutuskan objek pulpa dengan objek lainnya. Selanjutnya setelah dilakukan erosi pada citra, akan dilakukan operasi opening. Operasi ini berguna untuk menghapus atau menghilangkan area yang memiliki luas yang kecil. Sehingga objek kecil yang tersisa akibat erosi citra dan bukan merupakan pulpa akan terhapus.

\subsubsection{Deteksi Objek}

Pada bagian ini akan dilakukan seleksi yang hanya menyisakan objek pada bagian tengah. Dalam hal ini posisi pulpa yang akan diproses berada di tengah citra. Sehingga nantinya objek selain pulpa akan terdeteksi sebagai background dan tidak akan dihitung sebagai luas pulpa.

\subsection{Ekstraksi Ciri}

Ekstraksi ciri bertujuan untuk mendapatkan ciri khusus dari suatu citra yang menggambarkan karakter dari citra tersebut. Pada penelitian ini metode yang digunakan untuk mendapakan ciri yaitu binary large object. Proses ekstraksi ciri ini dilakukan setelah citra selesai memasuki tahap pre-processing. Melalui proses ini, maka didapatkan parameter-paramer penting dari setiap citra yang nantinya akan disimpan dalam database untuk proses pelatihan dan klasifikasi.

\subsection{Klasifikasi}

Setelah mendapatkan ciri yang diperlukan, selanjutnya data dikelompokkan berdasarkan kelas menggunakan klasifikasi decision tree. Proses klasifikasi ini akan dilakukan dengan mengolah ciri dari setiap citra, ciri yang sudah terkumpul dalam database akan memasuki proses pelatihan kembali menggunakan klasifikasi decision tree untuk diidentifikasi berdasarkan aturan yang dibuat. Apabila citra sudah sesuai dengan target maka akan disimpan dalam database latih. Untuk lebih jelasnya, proses dari klasifikasi sistem identifikasi usia ini dapat dilihat dalam diagram alur pada Gambar 9.

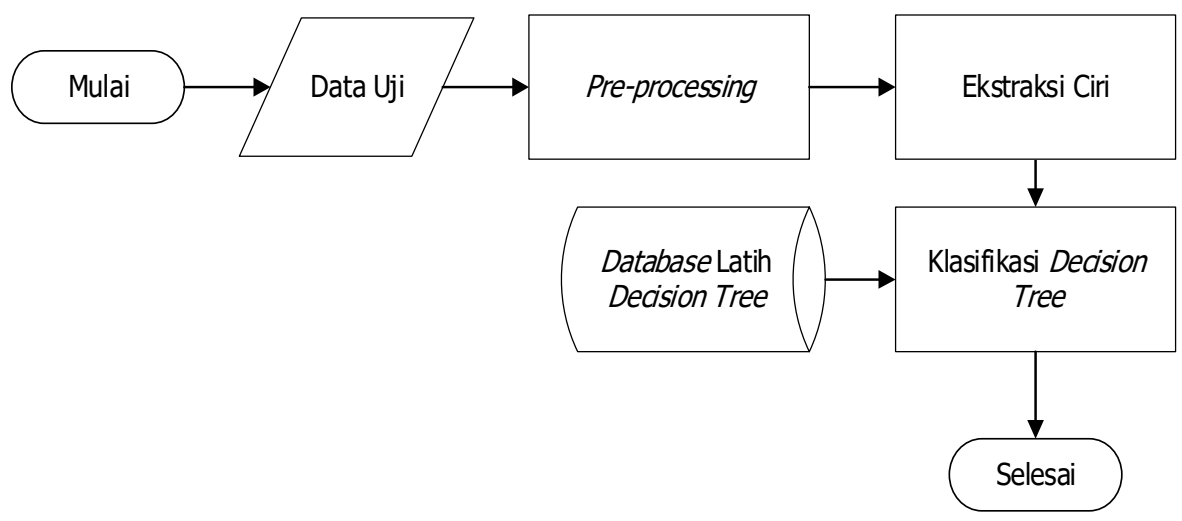

Gambar 9. Diagram Alur Klasisfikasi 
Perancangan Sistem Identifikasi Usia Manusia pada Citra Panoramic Radiograph Gigi Molar Pertama

Tahap pelatihan dengan decision tree ini, sistem akan membuat pola klasifikasi yang akan digunakan sebagai referensi prediksi kelas pada data. Untuk proses latih pada decision tree ini dilakukan dengan database yang berisi ciri latih hasil dari ekstraksi dengan $B L O B$ sebelumnya yang berupa matriks ciri latih berukuran $284 \times 3$. Selanjutnya hasil dari pelatihan ini ditentukan akar pohon yang berguna untuk membuat kelas yang telah ditentukan. Setelah terbentuk database latih. Selanjurnya akan dilakukan proses uji untuk mengetahui performa sistem yang telah dirancang.

\section{PENGUJIAN DAN ANALISIS SISTEM}

\subsection{Pengujian Sistem}

Secara garis besar, pengujian sistem ini dilakukan dengan memasukkan sekelompok citra panoramik radiograf gigi yang kemudian akan didapatkan output berupa nilai dari parameter uji, yang mana parameter pengujian yang digunakan dalam penelitian ini yaitu akurasi.

Pengujian sistem pada penelitian ini dilakukan dengan beberapa skenario yang berbeda terhadap 376 data yang dibagi menjadi 284 data latih dan 92 data uji. Untuk parameter pengujian sistem ini diambil berdasarkan parameter yang terdapat pada metode preprocessing, ekstraksi ciri dan klasifikasi yang digunakan dalam sistem. Selanjutnya, pengujian sistem ini dibuat menjadi tiga skenario yang didalamnya dilakukan optimasi pada parameter sistem yang berbeda. Adapun skenario pengujian sistem diuraikan lebih jelasnya sebagai berikut:

1. Skenario pertama dilakukan dengan mengubah jenis dan ukuran structuring element yang digunakan pada tahap pre-processing. Bertujuan untuk mendapatkan jenis dan ukuran structuring element yang menghasilkan performa sistem yang maksimal.

2. Skenario kedua adalah dengan mencoba berbagai kombinasi dari parameter ciri yang diambil. Ciri yang dimaksud yaitu area pulpa, rasio pulpa dan bbox. Tujuannya dilakukannya pengujian skenario ini untuk mendapatkan kombinasi parameter ciri yang menghasilkan tingkat akurasi yang tinggi.

3. Skenario ketiga yaitu mencoba jenis algoritma predictor selection serta melakukan pembatasan jumlah percabangan pada metode klasifikasi decision tree untuk membandingkan tingkat akurasi sitem terhadap tingkat kompleksitas sistem

Selanjutnya, pengujian sistem ini dibuat menjadi tiga skenario yang hasil berserta analisis akan disajikan dalam bentuk tabel dan grafik.

\subsection{Hasil dan Analisis Skenario Pertama}

Pada skenario ini dilakukan perbandingan nilai akurasi berdasarkan besar ukuran structuring element (strel). Dalam sistem yang telah dirancang, strel digunakan pada bagian preprocessing yaitu berfungsi dalam proses erosi citra yang bertujuan untuk mengikis tepian objek pulpa gigi yang berbentuk citra biner agar tidak menyatu dengan bagian latar belakang citra.

Untuk proses pengujian ini, akan dicoba menggunakan berbagai jenis dan ukuran stre/ yang berbeda. Jenis strel yang digunakan diantaranya yaitu disk, square dan diamond. Selain itu juga akan dicoba mengubah ukuran jari-jari dari masing-masing strel tersebut. Dan untuk pengujian ini, parameter ciri yang dipakai adalah seluruh parameter ciri yang digunakan dalam sistem identifikasi usia yaitu area pulpa, rasio pulpa dan bbox. Serta untuk parameter yang digunakan dalam metode klasifikasi decision tree juga masih menggunakan parameter default. Untuk hasil pengujiannya ditampilkan dalam Tabel 1. 
Tabel 1. Hasil Pengujian Sistem dengan Mengubah Nilai Threshold

\begin{tabular}{|c|c|c|}
\hline $\begin{array}{c}\text { Structuring } \\
\text { Element }\end{array}$ & $\begin{array}{c}\text { Radius } \\
\text { (piksel) }\end{array}$ & Akurasi (\%) \\
\hline \multirow{6}{*}{ Square } & 1 & 57.44 \\
\hline & 2 & 61.70 \\
\hline & 3 & 67.02 \\
\hline & 4 & 52.12 \\
\hline & 5 & 61.70 \\
\hline & 6 & 68.08 \\
\hline \multirow{6}{*}{ Disk } & 1 & 58.51 \\
\hline & 2 & 63.82 \\
\hline & 3 & 61.70 \\
\hline & 4 & 73.40 \\
\hline & 5 & 67.02 \\
\hline & 6 & 56.38 \\
\hline \multirow{6}{*}{ Diamond } & 1 & 58.51 \\
\hline & 2 & 63.82 \\
\hline & 3 & 65.95 \\
\hline & 4 & 69.14 \\
\hline & 5 & 69.14 \\
\hline & 6 & 57.44 \\
\hline
\end{tabular}

Dari Tabel 1 dapat dilihat bahwa perbedaan jenis dan ukuran stre/dapat memengaruhi tingkat kebenaran dari hasil uji sistem identifikasi usia. Disimpulkan bahwa jenis stre/ terbaik yaitu dengan menggunkan jenis disk dengan jari-jari 4 piksel yang menghasilkan performa sistem tertinggi dengan tingkat akurasi $73.40 \%$.

Kemudian dapat disimpulkan bahwa peforma sistem hanya maksimal pada satu jenis dan ukuran strel yang dianggap paling cocok untuk proses segmentasi. Hal tersebut disebabkan karena ukuran structuring element yang tepat akan menghasilkan segmentasi blob pulpa yang baik.

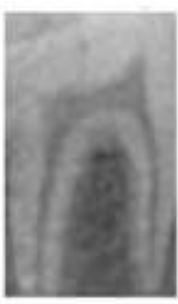

(a)

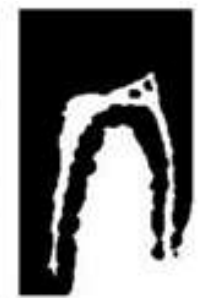

(b)

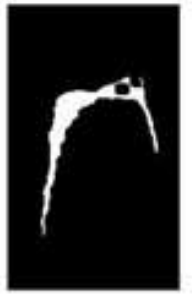

(c)

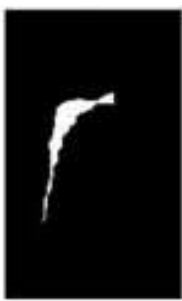

(d)

Gambar 10. Perbandingan Citra Hasil Erosi: (a) Citra Asli; (b) Citra Erosi Terlalu Kecil; (d) Citra Erosi yang Pas; (c) Citra Erosi Terlalu Besar

Pada Gambar 10 (a) merupakan citra asli sebelum memasuki proses sistem yang bisa digunakan sebagai pembanding. Untuk Gambar 10 (b) merupakan citra yang mendapat erosi dengan stre/terlalu kecil sehingga blob pulpa belum terpisah dari objek lainnya. Dalam Gambar 10 (c) bisa dibilang citra yang mendapat erosi dengan strel yang pas sehingga bentuk dari blob pulpa hampir menyerupai aslinya dan tidak menempel pada objek manapun. Dan terakhir pada Gambar 10 (d) merupakan citra yang mendapat erosi dengan stre/terlalu besar sehingga blob pulpa yang didapatkan terlalu kecil dibandingkan dengan pulpa aslinya. Sehingga dapat diambil kesimpulan pada penelitian ini jenis stre/ yang akan digunakan dalam pre-processing 
sistem identifikasi usia yaitu disk dengan jari-jari 4 piksel menghasilkan akurasi sistem paling tinggi.

\subsection{Hasil dan Analisis Skenario Kedua}

Pada skenario kedua ini akan dilakukan analisis pengaruh penggunaan parameter ciri yang diambil sebagai parameter uji yaitu dengan mencoba delapan kombinasi dari parameter ciri yang diambil. Untuk ciri yang digunakan pada penelitian ini yaitu luas pulpa, rasio pulpa dan bbox. Pengujian ini akan dilakukan dengan menggunakan strel yang menghasilkan nilai akurasi sistem paling tinggi yaitu disk dengan jari-jari 4 piksel. Untuk algoritma klasifikasi decision tree menggunakan predictor standar dan jumlah kelas masih belum dibatasi. Dan untuk hasil pengujian skenario ini ditampilkan pada Tabel 2 di bawah:

Tabel 2. Hasil Performa Sistem Skenario Kedua

\begin{tabular}{|c|c|c|c|c|}
\hline \multirow{2}{*}{$\begin{array}{c}\text { Kombinasi } \\
\text { Ke- }\end{array}$} & \multicolumn{3}{|c|}{ Parameter } & \multirow{2}{*}{ Akurasi } \\
\cline { 2 - 4 } & $\begin{array}{c}\text { Area } \\
\text { Pupa }\end{array}$ & $\begin{array}{c}\text { Rasio } \\
\text { Pulpa }\end{array}$ & Bbox & \\
\hline 1 & & & $\checkmark$ & 70.21 \\
\hline 2 & & $\checkmark$ & & 72.34 \\
\hline 3 & $\checkmark$ & & & 79.78 \\
\hline 4 & & $\checkmark$ & $\checkmark$ & 69.14 \\
\hline 5 & $\checkmark$ & & $\checkmark$ & 70.21 \\
\hline 6 & $\checkmark$ & $\checkmark$ & & 80.85 \\
\hline 7 & $\checkmark$ & $\checkmark$ & $\checkmark$ & 73.40 \\
\hline
\end{tabular}

Selanjutnya dilakukan percobaan dengan membuat kombinasi dari tiga fitur tersebut. Dan dari Tabel 2 ditampilkan tujuh kombinasi dari tiga fitur ciri yang digunakan. Dan untuk hasil terbaik yaitu dengan menggunakan kombinasi ke- 6 yaitu area pulpa dan rasio pulpa yang menghasilkan akurasi tertinggi sebesar $81,52 \%$. Untuk ciri bbox hanya menghasilkan tingkat akuasi $69,56 \%$ hal ini disebabkan karena ciri bbox yang diambil yaitu area yang berbentuk persegi panjang dengan mengambil bagian paling tepi pada pulpa. Luas atau area dari $b b o x$ tidak tidak efektif bila digunakan untuk menghitung luas pulpa. Sehingga dapat disimpulkan untuk ciri bbox tidak cocok digunakan pada bentuk pulpa yang cenderung berbentuk sirkular.

\subsection{Hasil dan Analisis Skenario Ketiga}

Skenario ketiga ini akan dilakukan pengubahan terhadap batas percabangan dan jenis algoritma pemilihan predictor yang ada di dalam metode klasifikasi decision tree. Untuk jenis algoritma pemilihan predictor yang ada di dalam metode decision tree yaitu allsplits dan curvature. Tujuan dilakukannya percobaan pada skenario ketiga ini yaitu untuk mendapatkan algoritma yang cocok digunakan untuk sistem identifikasi usia, selain itu juga pembatasan terhadap jumlah percangan bertujuan untuk mengontrol tingkat kompleksitas minimal yang dapat menghasilkan peforma sistem yang maksimal. Al/split merupakan algoritma yang digunakan secara default pada metode klasifikasi decision tree. Algoritma ini melakukan pememilihan predictor yang memaksimalkan perolehan gain informasi. Sedangkan untuk algoritma curvarture merupakan algoritma pememilihan predictor dengan melakukan uji kelengkungan (kurva) untuk mendapatkan sebuah pemisah.

Dari masing-masing predictor tersebut akan dicoba bersamaan dilakukan pembatasan jumlah percabangannya. Dan untuk batas percabangan yang digunakan pada skenario ini mulai dari 1 cabang dan akan bertambah dengan kelipatan 10 percabangan. Hal ini agar dapat menampilkan perbedaan hasil akurasi yang signifikan. Dan berikut pada Tabel 3 merupakan hasil dari pegujian skenario ketiga. 
Tabel 3. Pengaruh Parameter Decision Tree terhadap Performa Sistem

\begin{tabular}{|c|c|c|}
\hline Jenis Predictor & $\begin{array}{c}\text { Jumlah } \\
\text { Cabang }\end{array}$ & Akurasi (\%) \\
\hline \multirow{4}{*}{ Allsplits } & 1 & 50 \\
\cline { 2 - 3 } & 10 & 77.65 \\
\cline { 2 - 3 } & 20 & 74.46 \\
\cline { 2 - 3 } & 30 & 74.46 \\
\cline { 2 - 3 } & 40 & 75.53 \\
\cline { 2 - 3 } & 50 & 79.78 \\
\hline \multirow{4}{*}{ Curvature } & 60 & 80.85 \\
\cline { 2 - 3 } & 1 & 50 \\
\cline { 2 - 3 } & 10 & 80.85 \\
\cline { 2 - 3 } & 20 & 75.53 \\
\cline { 2 - 3 } & 30 & 75.53 \\
\cline { 2 - 3 } & 40 & 78.72 \\
\cline { 2 - 3 } & 50 & 82.97 \\
\hline
\end{tabular}

Dapat dilihat pada Tabel 3 menampilkan hasil akurasi sistem tertinggi diperoleh dengan menggunakan algoritma curvature yang menghasilkan tingkat akurasi $82.97 \%$. Kemudian dengan menggunakan algoritma allsplit, sistem mendapatkan tingkat akurasi 80,85\%, yang mana itu lebih kecil bila dibandingkan dengan menggunakan algoritma curvature. Hal ini disebabkan algoritma allsplit hanya membuat rule decision tree dengan memilih predictor yang memaksimalkan gain informasi, dengan kata lain pada algoritma allsplit ini kurang memperhatikan perbedaan yang tipis pada data, sedangkan untuk algoritma curvature tedapat proses uji kelengkungan yang bertujuan untuk membuat predictor pemisah antara data yang perbedaannya kecil. Pada data penelitian ini antar usianya memiliki perbedaan luas pulpa yang kecil, sehingga jenis algoritma yang cocok untuk sistem identifikasi usia adalah jenis curvature. Dan pada penelitian ini hanya dilakukan percobaan membatasi jumlah percabangan dari 1 sampai dengan 60 percabangan. Hal ini dikarenakan walaupun jumlah percabangannya terus ditambah, nilai dari akurasi, pada sistem sudah mencapai maksimal. Hal tersebut dapat diperjelas dengan grafik dalam Gambar 11 yang manampilkan nilai akurasi setelah dilakukan percobaan sampai dengan 100 percabangan.

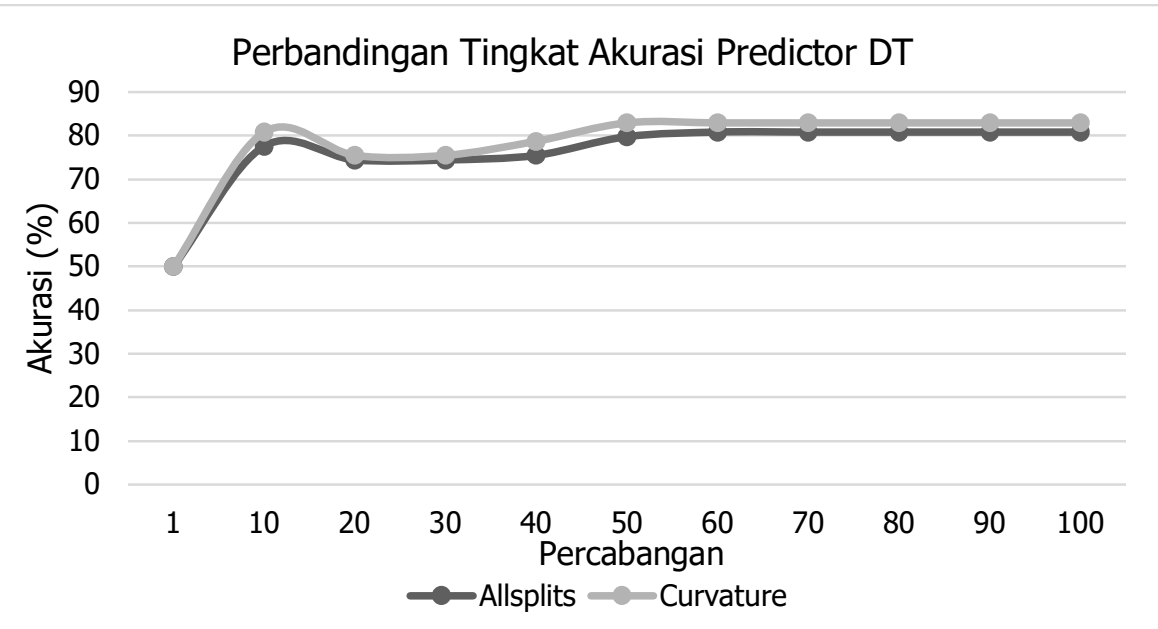

Gambar 11. Grafik Pengaruh Jumlah Percabangan terhadap Performa Sistem 
Perancangan Sistem Identifikasi Usia Manusia pada Citra Panoramic Radiograph Gigi Molar Pertama

Terlihat grafik pada Gambar 11, jumlah percabangan 50 sampai dengan 100 menghasilkan performa sistem yang sama pada kedua algoritma dan sudah bisa dibilang maksimal. Pengubahan pada batas percabangan decison tree ini sangat berpengaruh bagi performa sistem identifikasi usia. Hal tersebut diakibatkan karena semakin banyak percabangannya akan semakin kompleks kerja sistem dan akan membuat proses klasifikasi menjadi lebih akurat. Dan sedikit percabangan sama saja dengan membatasi jumlah rule yang terbentuk pada decision tree, serta pada jumlah percabangan tertentu, decision tree akan menghasilkan nilai akurasi yang rendah, hal tersebut dikarenakan rule yang dibentuk oleh decision tree belum lengkap.

Namun jumlah percabangan dari sistem decision treejuga akan menyesuaikan dengan tingkat kerumitan dari sebuah data. Dan data yang digunakan dalam penelitian ini dapat diproses dengan optimal dengan hanya menggunakan 50 batas percabangan. Sehingga untuk sistem identifikasi usia jenis algoritma pemilihan predictor batas percabangan yang optimal yaitu curvature dengan jumlah 50 percabangan.

\section{KESIMPULAN}

Berdasarkan hasil pengujian pada sistem pada penelitian tugas akhir ini telah berhasil dirancang sebuah sistem berbasis pengolahan citra digital yang mampu mengidentifikasi usia manusia pada citra radiograf panoramic gigi molar pertama dengan menggunakan metode Binary Large Object $(B L O B)$ dan klasifikasi Decision Tree. Sistem yang dirancang memiliki tingkat akurasi lebih dari $80 \%$, dan dapat bekerja secara optimal apabila citra yang digunakan memiliki kualitas citra yang baik dan bentuk pulpa terlihat jelas. Dan parameter yang berpengaruh dalam sistem yang dirancang pada penelitian ini yaitu jenis dan ukuran structuring element pada proses segmentasi, penggunakan fitur ciri $B L O B$ dan penggunaan jenis algoritma pemilihan predictor serta jumlah percabangan pada metode decision tree serta kualitas citra gigi yang digunakan.

\section{DAFTAR RUJUKAN}

Budi, A. T. (2014). Peran restorasi gigi dalam proses identifikasi korban (The role of dental restoration in victim identification). Journal of the Indonesian Dental Association, 63(2), $41-45$.

George, Paul \& Satish, K. V. (2008). Forensic Medicine and Toxicology. In The American Journal of the Medical Sciences, 75(149), 181-191.

Greensted, A. (2009). Blob Detection. The Lab Book Pages.

Haris, M., Hidayat, B., \& Oscandar, F. (2019). Deteksi Usia Berdasarkan Citra Panoramik Pulpa Gigi Molar Pertama Mandibula Dengan Menggunakan Discrete Wavelet Transform (DWT) Dan Klasifikasi Decision Tree, 5(1), 1-7.

Jafar, A., Kadafi, A., \& Utaminingrum, F. (2018). Deteksi Objek Penghalang Secara Real-Time Berbasis Mobile Bagi Penyandang Tunanetra Menggunakan Analisis Blob. Jurnal Pengembangan Teknologi Informasi Dan IImu Komputer (J-PTIIK) Universitas Brawijaya, 2(1), 423-432. 
Kadir, A., \& Susanto, A. (2013). Teori dan Aplikasi Pengolahan Citra.

Kurniawati, E. I., Hidayat, B., \& Oscandar, F. (2018). Deteksi Usia Berdasarkan Pengolahan Citra Panoramic Radiograf Gigi Molar Pertama Mandibular Dengan Metoda Histogram Of Oriented Gradient Dan Klasifikasi Learning Vector Quantization. Development, $134(4), 4750-4757$.

Kusumaningtias, R., Hidayat, B., \& Oscandar, F. (2019). Deteksi Usia Berbasis Citra Radiograph Panoramic Dengan Metode Gray Level Co-Occurence Matrix (GLCM) Serta Klasifikasi Learning Vector Quantization (LVQ), 5(3), 1-9.

Maulana, H. (2016). Analisa Perbandingan Hasil Pohon Keputusan Dengan Gain Ratio, Information Gain, Dan Gini Index Pada Pemasaran Produk Herbal di CV. Al - Ghuroba.

Munir, R. (2004). Pengolahan Citra Digital dengan Pendekatan Algoritmik. In Penerbit Informatika.

Munir, R. (2012). Matematika Diskrit. Penerbit Informatika Bandung.

Nelson, S. J. (2014). Dental Anatomy, Physiology, and Occlusion (10th ed.). Elsevier.

Putri, A. S., Nehemia, B., \& Soedarsono, N. (2013). Prakiraan usia individu melalui pemeriksaan gigi untuk kepentingan forensik kedokteran gigi. Pdgi, 62(3), 55-63.

Rachmawati, F., Hidayat, B., \& Oscandar, F. (2018). Identifikasi Usia Berdasarkan Pengolahan Citra Panoramik Molar Pertama Mandibula Dengan Metode Discrete Cosine Transform (Dct) Dan Klasifikasi K-Nearest Neighbor (K-Nn). 5(3), 4924-4931.

Rashmi, G., Basavaraj, S., NK, P., \& Rathore, R. (2014). Textbook of Dental Anatomy, Physiology and Occlusion. In Textbook of Dental Anatomy, Physiology and Occlusion.

Senn, D. R., \& Stimson, P. G. (2010). Forensic Dentistry 2nd Edition.

Surashadarti, N., Hidayat, B., \& Suhardjo. (2018). Sintesa Penelitian Deteksi Kista Periapikal Radiograf Dengan Metode Binary Large Object (BLOB) Dan Metode Gray Level CoOccurence Matrix (GLCM) Research. E-Proceeding of Engineering, 5(3), 5538-5545.

Syafi'i, S. I., Wahyuningrum, R. T., \& Muntasa, A. (2016). Segmentasi Obyek Pada Citra Digital Menggunakan Metode Otsu Thresholding. Jurnal Informatika, 13(1), 1-8.

Watanabe, P. C. A., Faria, V., \& Camargo, A. J. (2017). Multiple Radiographic Analysis (Systemic Disease): Dental Panoramic Radiography. 